\title{
APPLICATION OF GIS AND REMOTE SENSING TO MONITOR THE IMPACT OF DEVELOPMENT ACTIVITIES ON THE COASTAL ZONE OF JAZAN CITY ON THE RED SEA, SAUDI ARABIA
}

\author{
Aaid G. Al-Zubieri ${ }^{1}$, Rashad A. Bantan ${ }^{1}$, Rifaat Abdalla ${ }^{2}$, Satria Antoni ${ }^{1}$, Talha A. Al-Dubai ${ }^{1}$, and Jawad Majeed \\ ${ }^{1-D e p a r t m e n t ~ o f ~ M a r i n e ~ S c i e n c e, ~ F a c u l t y ~ o f ~ M a r i n e ~ S c i e n c e, ~ K i n g ~ A b d u l a z i z ~ U n i v e r s i t y, ~ J e d d a h, ~ S a u d i ~ A r a b i a ~-~}$ \\ aahmed0217@stu.kau.edu.sa \\ 2-Department of Earth Science, Faculty of Science, Sultan Qaboos University, Muscat, Oman - rabdalla@ squ.edu.sa
}

KEY WORDS: Jazan, Remote Sensing, GIS, development activities, Red Sea

\begin{abstract}
:
Jazan city is a fast-growing coastal city in the southern part of Saudi Arabia, Red Sea. Recently, it has encountered quick industrial development activities. To monitor these activities, the changes in coastal zone morphology explore over the last 30 years (19872017) using GIS and remote sensing techniques. Four satellite images (TM and ETM) acquired during these intervals were performed. Furthermore, a development and growth of the city were created based on direct digitizing from Google Earth Pro to identify the extension and expansion of the area of study during this period. The magnitudes of erosion, deposition, and landfilling at differential scales through the period of study were determined using photo-interpretation on the changes of surface area and the extension of the city landward. The results illustrated remarkable changes and shifting of shoreline seaward along the coast and extending of dwelling zone in the city. Erosion and accretion take place mostly in the earlier interval (1987-2000) in some parts of the coast followed by landfilling occurring in the northern and middle parts of the coastal area in the interval (2000-2013). However, the magnitudes were different from interval to interval. The relative changes were $14.33,58.56$, and $27.11 \%$ at the periods from 1987-2000, 2000-2013, and 2013-2017, respectively. However, dwelling zone extended dramatically from $23.31 \mathrm{~km}^{2}$ in 1987 , to $25.32 \mathrm{~km}^{2}$ in $2000,63.37 \mathrm{~km}^{2}$ in 2013 , and to reach $67.90 \mathrm{~km}^{2}$ in 2017 . These changes probably attributed to human activities in the coastal area due to construct a new economic city in the northern part during the period between 2003 and 2013 along with different socio-economic activities. The tidal flat in front of the city is shrunk due to this landfilling. This landfilling has been destructed a wide range of mangrove ecozones and possibly impacted the biotics in the area.
\end{abstract}

\section{INTRODUCTION}

\subsection{General statements}

Red Sea coastal line with an extension of around $1800 \mathrm{~km}$ is the one of the very special and principal geomorphological feature of Saudi Arabia, along which anthropogenic activities are playing a vital role. There are enormous human activities along Red Sea coast. There are many reason for coastal degradation and many are directly related to the development projects along the coastal area, and all these factors along local development projects puts a great impact on coast. Besides this, very slow and steady coastal degradation couldnot be neglected, which not only triggers the rise in sea level but also helps to accelerates the many coastal hazards. Creating strategies to balance protection of individuals and the economy against the expenses of disintegration of the beach front ecozone will require multidisciplinary clarify about (Nicholls et al., 2007). Jazan coastal area is formed an important part of this geographic feature in Saudi Arabia. As the area is situated at the southwestern border of country which emphasis to the importance on the geographic location of the city, so in this context, Saudi government started many developmental works in the area (Youssef et al., 2012). They also mentioned about different geological hazards that currently area of Jizan is suffering. Some of them that could have hazardous impact includes the Sabkhas, salt domes, windblown sand dunes, loess- palaeosol, and seasonal flash floods that are effecting through historical time. Continuation of mentioned hazards could be of risk with possible rise in sea-level along Jazan coastline.
In Jazan, various authors in the previous years have studied different geotechnical characteristics of Jazan (e. g. Dhowian et al. 1987; Dhowian 1990; Erol 1989; Al-Shamrani and Dhowian 1997). In recent years, a few of studies have interested in Jazan based on remote sensing and GIStechnology (Youssef et al., 2012; AL-Sheikh and Yahiya, 2012). Recent study by AL-Sheikh and Yahiya (2012) concludes severe effect of environmental degradation of Jazan coast and reveals that the vegetation cover was lost approximately $46 \%$ between 1987 and 2002 by using GIS and RS techniques. The present study is focus to monitor and to infer coastal zone changes that could attribute to the identify possible upcoming hazards caused by development activities along Jazan coast, to understanding the dynamics of coastal area and in terms of its performance, policy decision making and successful landscape management makes GIS technology utility as an effective tool and representing coastal area that subjected discuss a number of efforts and risks for developmental activities that can threaten new development activities with the Jazan Coast.

\subsection{Area of study}

Area of study is the capital of Jazan region which is situated in the extreme southwestern part of Saudi Arabia close to the border of Saudi Arabia and Yemeni lies between $42^{\circ}$ and $43,8^{\circ} \mathrm{E}$ and $16,5^{\circ}$ and $17^{\circ}$ North (Fig. 1). It has the third largest port in Saudi Arabia and it's the main gateway to Farasan Island. As of 2004 census, the residents of Jazan was about 255340 with $21.52 \%$ of the total population of Jazan region and 5.2. In contrast, the population reduced to reach 
163703 at 2010. Temperature gradient varies $29^{\circ}-38.5^{\circ} 29$ ${ }^{\circ}$ and $21^{\circ}-30^{\circ}$ during spring and winter respectively. In last decade, humidity record was fluctuating in between $6 \%-68 \%$ and sometimes reached maximum value of $100 \%$. It is relatively high. The coastal area common winds in the locality are blown in W-SW direction with an average speed of $12 \mathrm{~km} / \mathrm{h}$ (AL-Sheikh and Yahiya, 2012).

As economic perspective, Jazan is a fast-growing coastal city and the most important agricultural areas in the southern part of Saudi Arabia, where diverse crops, and most famous of these crops, Mango and Papaya, as well as a number of other agricultural crops. On the other hand, It is considered as a rich in fisheries due to the abundant appropriate environmental factors for the growth and prosperity of the fisheries along the territorial waters and coasts. These factors are leading to the availability of commercial fish species throughout the year, such as Aldrak (kingfish) and grouper and Alshour and Albiadh and Akaka to besides shrimp and other crustaceans, molluscs. In addition, it is among the most attractive tourist area in Saudi Arabia as a consequence of its shifted geology and differentiating territory and incorporates mud coasts, sandy shorelines, delightful islands, fields, regular backwoods, valleys and high mountains.

The coastal area extends from the El-Darb city in the north to the Samtah city in the south with wide of tidal flat and is characterized by a high prevalence of marshes, mangrove environment, and salt marshes. Many valleys are discharging into Red Sea along the coast, causing the floods that rundowns from the east west oriented mountains. Jazan Valley is one of the most famous valley that flanks an area of around $200 \mathrm{~km}$, the Lagab Valley with a length approximately $200 \mathrm{~km}$, and the Sebya Valley with length 250 $\mathrm{km}$ (AL-Sheikh and Yahiya, 2012). These valleys discharge a huge of sediments to the coastal area.
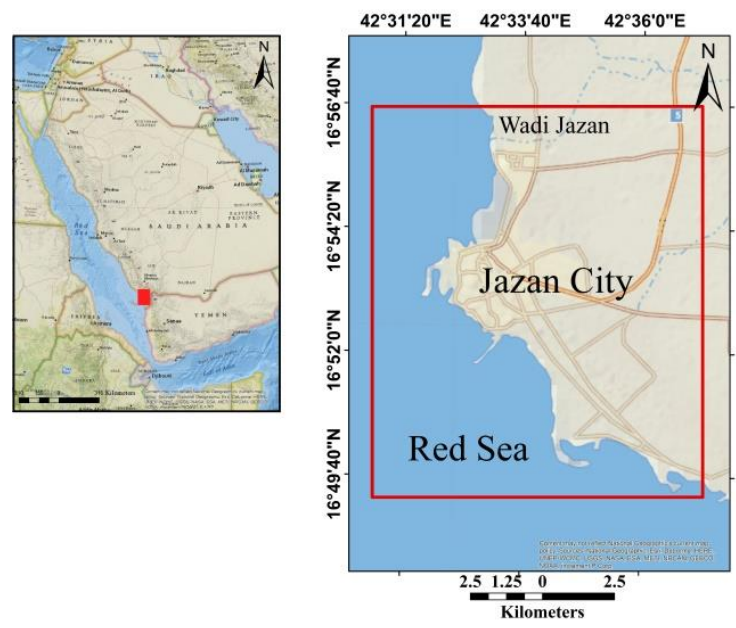

Figure 1 GIS based location map of the area showing the location of Jazan city and Wadi Jazan.

\section{METHODOLOGY AND DATASETS}

The methodological framework applied in the study can be divided into two sections; the first section deals with acquisition of data, Image co-registration and enhancement using ERDAS IMAGINE 2014, while the second section extracts shoreline and boundary of Jazan City through manually digitizing and different processes of spatial analysis using ArcGIS 10.3 package and presents the results. The methodological structure is shown in the flow chart below.

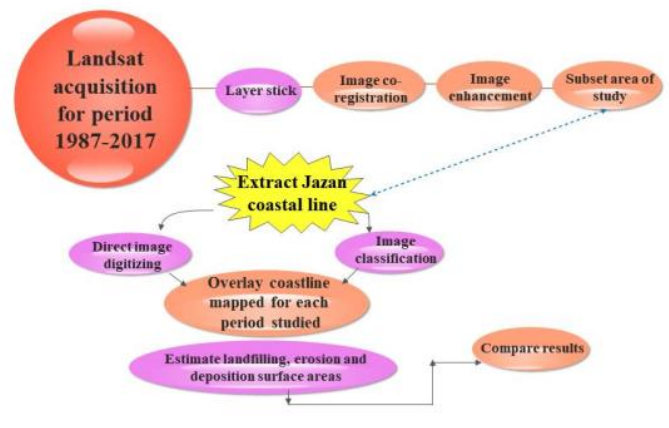

Figure 2 Methodology flow chart

\subsection{Datasets}

\subsubsection{Geospatial datasets}

Landsat information is the main multispectral satellite information easily open accessible giving a succinct scope of the Earth extending back to 1972. In this manner, Landsat information have a one of a kind esteem and this clarifies the utilization and phenomena of examining different ecological processes to monitor, including changes along coastline (e. g. Thampanya et al., 2006; Li and Damen, 2010; Durduran, 2010; Cui and Li, 2011; and Petropoulos et al., 2015). . In this study, four Landsat 7 (TM and ETM) digital satellite imageries (Path [167] / Row [48]) captured for the period from January 1987 to January 2017 with interval 5 years were acquired. These data were obtained from (glovis.usgs.gov and eos.com/land viewer) website. In addition, boundaries of the area of study for the period was generated by digitizing the information from satellite imagery of Google Earth Pro.

\subsubsection{Non-spatial data sources}

Notwithstanding the previously mentioned spatial information, non-spatial information related to the population, residential buildings, industrial zones, and various socio-economic information such as agriculture, fishing, and urbanization was also acquired. All of these data were from the population census data and a general authority for statistics of Saud Arabia.

\subsection{Coastline extraction}

Based on the image interpretation, a direct digital processing was applied to reduce the changes as well along the coastal area from the satellite imagery at 1987, 2000, 2013, and 2017 dates for the area of study. In addition, a manual digitization processes based Google Earth Pro was used to extract the boundary of the city at different dates. A review of the flowchart used to address and to achieve the objectives of proposed study is shown in Fig. 2. The strategies for preprocessing the information are depicted next, trailed by the portrayal of the coastlines extraction techniques and investigation approach.

\subsection{Pre-processing}

ERDAS 2014 and ArcGIS (v. 10.3) package were used to pre-process the geospatial analyses for the spatial datasets. 
To start with, the TM and ETM images were transported in into Erdas and changed over to radiance values (Irons, 2011). Accordingly, for each of satellite imagery, layer stacked were performed for all the sensor spectral bands to shape a single image file relating to the acquisition date of the dataset. The final images were processed by enhancement tools. Then an empirical line normalization and controlling points to all images were actualized utilizing the 1987 image as a base using ArcMap. This is a relative barometrical revision technique used to moderately coordinate the climatic impacts which give a simple method to remedy for brilliance/reflectance varieties because of sun based brightening condition, phenology and indicator execution corruption (Latifovic et al., 2005). Consequently, coregistration process for the TM and ETM images was carried out in Erdas and geometric registration process was performed usin ArcMap. With a specific end goal to break down satellite imagery from different dates and become in the same spatial reference outline (Schmidt and Glaesser, 1998 and Petropoulos et al., 2015).

\subsection{Mapping of Coastline area}

This section depicts in precisely the means taken in extricating the shoreline from the satellite imagery utilizing the methodologies utilized, in particular, the immediate digitization through the photograph elucidation of the gained Landsat images, calculate the changes area, and figure the progressions region. Satellite information feature band (RGB 3-2-1 genuine nature composite) was used to capture the beach from each image. To enhance extraction of coastlines, RGB groups $7(2.08-2.35 \mu \mathrm{m}), 4(0.76-0.90 \mu \mathrm{m})$, and 2 $(0.52-0.60 \mu \mathrm{m})$ were the best for partition amongst land and water and piece of groups $4(0.76-0.90 \mu \mathrm{m}), 3(0.63-0.69$ $\mu \mathrm{m})$ and $2(0.52-0.60 \mu \mathrm{m})$ were best for vegetation. This is in concurrence with different scientists additionally utilizing TM and ETM information for coastlines mapping (e.g. Petropoulos et al., 2015). These standards were utilized as a part of specifically digitizing the coastline from the preprepared Landsat TM and ETM images. To calculate the coastline surface area changes and the extending of the city (in $\mathrm{km} 2$ ), Standard GIS processing capabilities between vectors of different dates of dataset were used as well as overlay coastlines mapped for each period studied.

\subsection{The change in the coastal zone ( erosion and landfilling estimation)}

A vector and raster examination methodology was utilized by using ArcMap GIS package (ESRI, v. 10.3) in order to evaluate the landfilling, disintegration percentage, eriosin and extension of the city area during 1987-2017 at different temporal scales by utilizing the standard GIS processing techniques (e.g. intersect, union, and clip). Specifically, the rates of surface change for the single time frames from 1987 to 2000,2000 to2013, 2013 to 2017 , and 1987 to 2017 were quantified in view of the shoreline surface area changes (in $\mathrm{km}^{2}$ ) contrasted with the underlying 1987 shoreline. Separations and zones of landfilling and erosion along the coastlline were then geometery calculated between the vectores. It is allowed to relate estimation between two datasets. It then allows to measure the extent of land filling and disintegration and geomorphology evolution with the slightest direction measured by each strategy. Comparable to earlier methodologies that have been executed in comparable examinations earlier (e.g. Durduran, 2010 and Petropoulos et al., 2015), the final estimation data were converted to the percentage using excel statistic and represented as pie and histogram chart.

\section{RESULT AND DISCUSSION}

\subsection{Shoreline changes}

The development activities on the coastal zone of Jazan city are influenced along the shoreline such as extensive accretion due to develop the seaport and construct several industrial zones. In addition, there is some deposition/erosion due to natural processes along of this zones. Moreover, a wide range of marine ecozones were destroyed due to these activities. Thus, the results of this study highlight significant accretion/erosion through the periods of study.

The results of shoreline maps show remarkable changes along the coast during the periods (Fig. 3). Generally, the shoreline shifted seawards in front of Jazan City during the period from 1987 to 2017. The highest changes were at the time interval between 2000 to 2013. The changes between 1987 to 2000 is in front of the old Jazan city and the lowest change when compared to the other period. The change between 2000 to 2013 is the largest changes and maybe cover the most coastal area. The most of changes between 2013 to 2017 are in the southern part of the coastal area. Fig. 4. Illustrates these changes as erosion in red color and deposition or landfilling in yellow color and the comparison between the total changes of surface area (in $\mathrm{km} 2$ ) for all of the investigated periods is shown in fig. $5 \mathrm{~A}$ as histogram bar. On the other hand, the relative magnitudes of landfilling or deposition and erosion are represented in table 1 and Fig. 5B. All of these figures show that the area along coastline have changed significantly during 2000 and 2013.

In general, the available dataset indicates landfilling was the predominant process operative along the coastal area between 1987 and 2017 which is even most strong in the northern part. However, the erosion within this period has been variable and negligible when compared it with landfilling. The most of erosion processes were in the southern part Fig. 4. The accretive/erosive are appeared along of the spits. This is maybe due to the effect of waves as well as human intervention. The total landfilling and deposition reached magnitudes of $15.76 \mathrm{~km} 2$ and erosion reached $2.01 \mathrm{~km} 2$ during 1987 to 2017 . However, the relative changes during the periods were $14.33,58.56$, and $27.11 \%$ at the periods from 1987-2000, 2000-2013, and 2013-2017, respectively. These changes probably attributed to human activities in the coastal area due to construct a new economic city in the northern part during the period between 2003 and 2013 along with different socio-economic activities. The tidal flat in front of the city is shrunk due to this landfilling. Landfilling has been affected the tidal flat, that possibly impacted the biotics in the area: the destruction of mangrove ecozone.

\begin{tabular}{|c|c|c|c|}
\hline Time period & $\begin{array}{c}\text { Landfilling and } \\
\text { deposition }(\mathrm{km} 2)\end{array}$ & $\begin{array}{c}\text { Erosion } \\
(\mathrm{km} 2)\end{array}$ & $\begin{array}{c}\text { Releativ } \\
\text { changes\% }\end{array}$ \\
\hline $1987-2000$ & 2.88 & 0.91 & 14.33 \\
\hline $2000-2013$ & 8.54 & 0.49 & 58.56 \\
\hline $2013-2017$ & 4.33 & 0.61 & 27.11 \\
\hline $1987-2017$ & 15.76 & 2.01 & 100 \\
\hline
\end{tabular}

Table 1 Magnitude of erosion, landfilling and deposition along the coastal area 

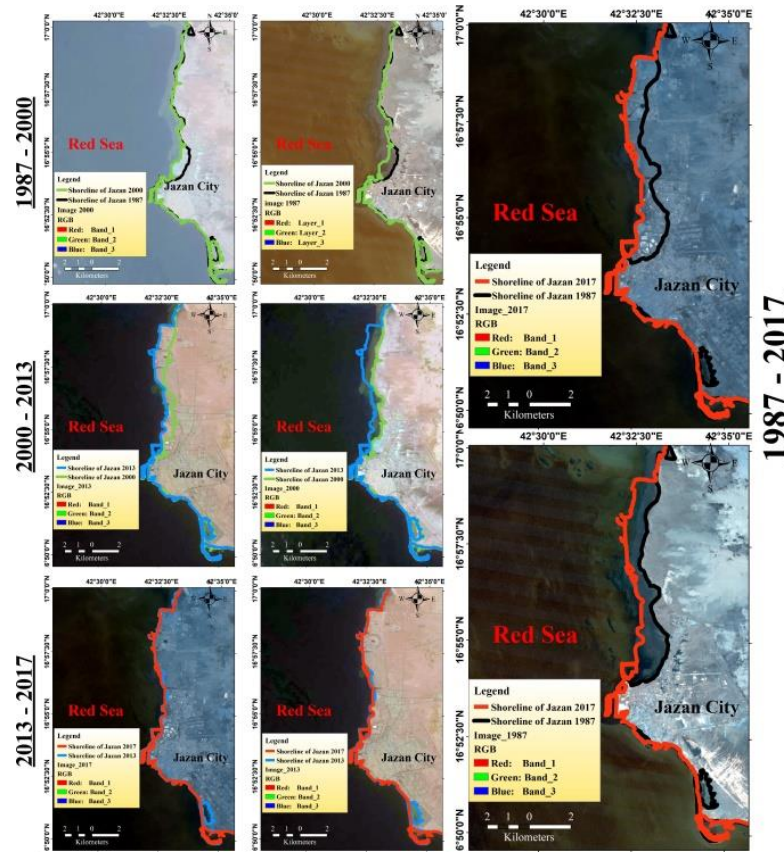

Figure 3 Maps showing shoreline changes in the investigated area

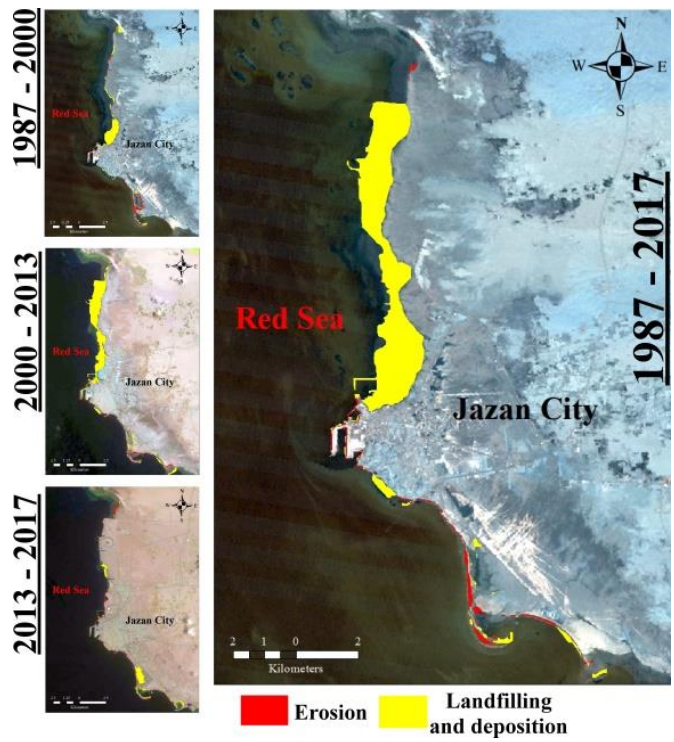

Figure 4 showing erosion, deposition and landfilling along the coastline in all period

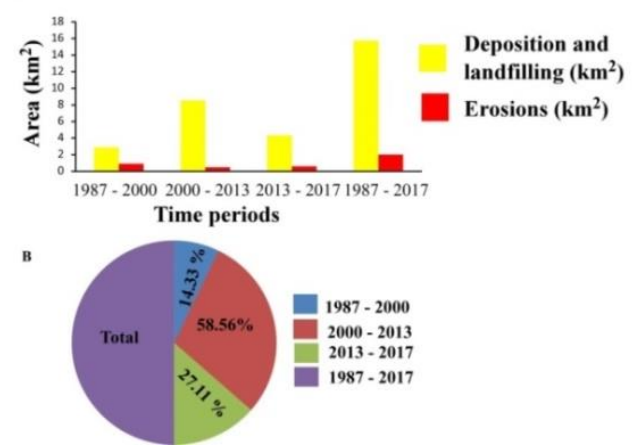

Figure 5 a) Erosion (red) and deposition or landfilling (yellow), b) the relative changes

\subsection{Development and growth of the study area}

The development and growth of Jazan city over 30 years from $(1987-2017)$ is shown in Fig. 6. This figure illustrates that the area of study growing gradually during the period 1987 to 2000 . However, the area was fast growing during the period from 2000 to 2013. This development is continuous dramatically til 2017. The dwelling zone increased from $23.31 \mathrm{~km} 2$ in 1987 to reach $25.32 \mathrm{~km} 2$ in 2000 with the relative of growth $4.5 \%$, to reach $63.37 \mathrm{~km} 2$ in 2013 with relative development $85.32 \%$, and to reach $67.90 \mathrm{~km} 2$ in 2017 with relative $10.16 \%$ as are represented in table 2 . These result interpreted as a relatively stable growth during the period 1987 - 2000 except some human intervention to construct Jazan Sea Port in the front old city. In addition, the population growth was gradually when compared to the recent period. Where the population in Jazan region was around 865961 and the total of housing units 140092 in 1992 and reach 1187587 and housing units are 177346 in 2004. However, a fast growth in the region was during the period $2000-2013$, where the population growth is reached around 1365110 and housing units increased to reach 199625. in the last period, there are also increased in the housing units and population. The population is growing to reach 1567547 in 2017. Moreover, a lot of industrial activities occurred during the period from 2000 to 2017. For example, The construction and expansion of Jazan Port, the city's architectural expansion and urbanization, the construction of a new industrial city in the northern part of the coastal region.

\begin{tabular}{|c|c|c|c|}
\hline Time period & $\begin{array}{c}\text { Dwelling } \\
\text { zones (km2) }\end{array}$ & Growth & $\begin{array}{c}\text { Relative } \\
\text { growth\% }\end{array}$ \\
\hline 1987 & 23.31 & - & - \\
\hline $1987-2000$ & 25.32 & 2.01 & 4.52 \\
\hline $2000-2013$ & 63.37 & 38.05 & 85.32 \\
\hline $2013-2017$ & 67.90 & 4.53 & 10.17 \\
\hline $1987-2017$ & 44.60 & 44.60 & 100 \\
\hline
\end{tabular}

Table 2 represents dwelling zone and the relative growth of the study area

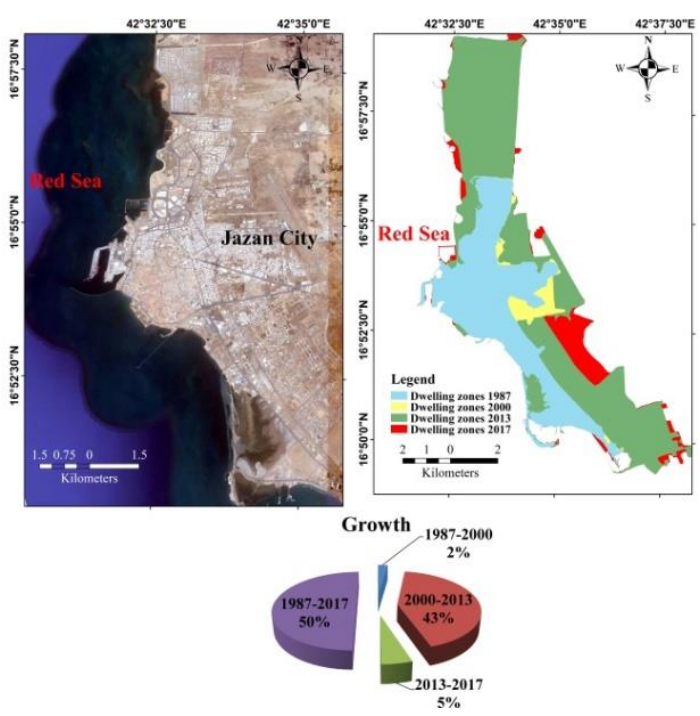

Figure 6. Maps showing the development of dwelling zones in the area of study over 30 years 


\subsection{Coastal changes and socio -economic activities}

Figures (7a-d) demonstrate the coastal zones superimposed on satellite images of Jazan, that display significant reclamation of the coastal zone both for the Port in front of old city and related infrastructure which has been evolved up to the driftage and additionally the beachfront changes in the northern district of the city caused by development and construct the economic city. As shown in the figure a wide range of tidal flat are filling especially at the northern distinct and in the middle of the coast due to these socio-economic activities. On the other hand, the desalination plant's jetty broadened assist offshore and the procuration down-float disintegration slant reached out finished a huge separation. Moreover, depending on the information from General Authority for statistics of Saudi Arabia, the number of establishments of economic activities in Jazan was around 16736 in 2001 and increased to reach around 28667 after 2010 and the most of these establishments are carries out its activities at the coastal zones. This means that the major changes along the coastal zone of the city are strongly influenced by these socio-economic activities. Consequently, a wide range of mangrove ecozones are destroyed, and possibly impacted the biotics in the area.
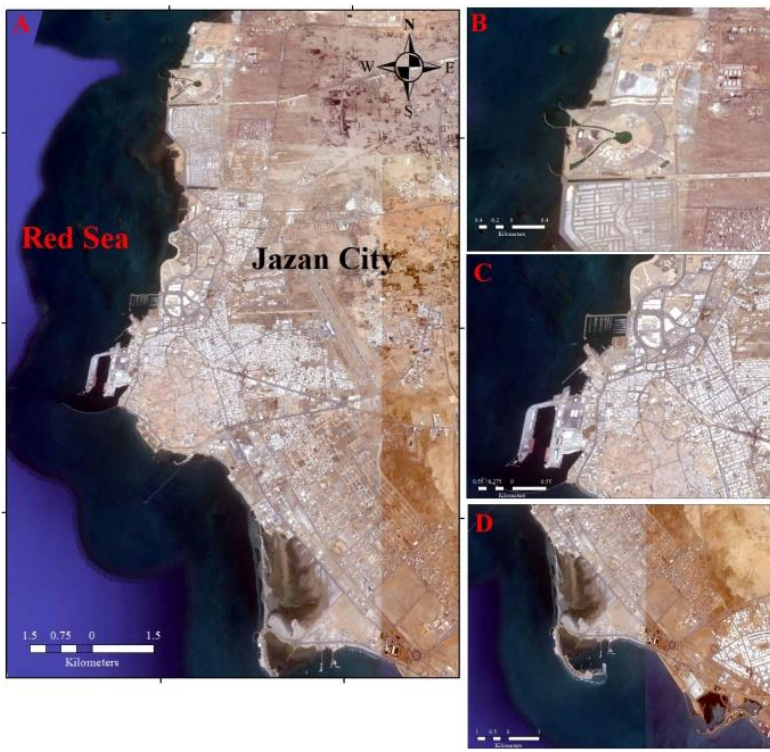

Figure 7 a) map show area of study, b) New economic city in the northern part, c) the development of seaport in the central of coastal area, and d) the development in the southern part

\section{CONCLUSIONS}

Monitoring of the changes and impact of development activities that have occurred in the coastal zone by utilizing integral connection between ArcGIS package and earth observation was very effective. The coastline along the study area was not linear but almost smooth and performed in many forms including curved, arc beaches, spits, salt marshes, and mangroves. In addition, the most of this coastal area recently are impacted by infrastructures, such as tourism, port development, and industrial activities.

The results indicate that the coastal zone of the study area are remarkably changed as shifting of shoreline seaward along the coast especially in the middle and northern part and the socio-economic activities play an important role for these changes. The tidal flat in front of the city is shrunk due to these socio-economic activities. A wide range of mangrove ecozones are destroyed, and possibly impacted the biotics with the coastal area. In addition, the city is growing continuously. Dwelling zone is considerably extended and expanded northward and landward. The unsustainable utilization of marine beach front area interfaces happens, where ecological measures were not considered, slighting the privilege of future ages in acquiring the marine regular. therefore, this study suggests it should evaluate the risks that probably demonstrate jeopardy to the development activities in future along Jazan coast through environmental assessments.

\section{References}

Alharbi, O.A., Phillips, M.R., Williams, A.T., Thomas, T., Hakami, M., Kerbe, J., Niang, A.J., Hermas, E. and Al-Ghamdi, K., 2017. Temporal shoreline change and infrastructure influences along the southern Red Sea coast of Saudi Arabia. Arabian Journal of Geosciences, 10(16), p.360.

Al-Shamrani, M.A. and Dhowian, A.W., 1997. Preloading for reduction of compressibility characteristics of sabkha soil profiles. Engineering Geology, 48(1-2), pp.19-41.

AL-Sheikh, A.B.Y., 2012. Environmental degradation and its impact on tourism in Jazan, KSA using Remote Sensing and GIS. International Journal of Environmental Sciences, 3(1), pp.421-432.

Chu, Z.X., Sun, X.G., Zhai, S.K. and Xu, K.H., 2006. Changing pattern of accretion/erosion of the modern Yellow River (Huanghe) subaerial delta, China: based on remote sensing images. Marine Geology, 227(1-2), pp.13-30.

Cui, B.L. and Li, X.Y., 2011. Coastline change of the Yellow River estuary and its response to the sediment and runoff (1976-2005). Geomorphology, 127(1-2), pp.32-40.

Dhowian, A.W., 1990. Simplified heave prediction model for expansive shale. Geotechnical Testing Journal, 13(4), pp.323-333.Dhowian, A. W., Erol, A. O., \& Sultan, S., 1987. Settlement predictions in complex sabkha soil profiles. Bulletin of Engineering Geology and the Environment, 36(1), 11-21.

Durduran, T., Choe, R., Baker, W.B. and Yodh, A.G., 2010. Diffuse optics for tissue monitoring and tomography. Reports on Progress in Physics, 73(7), p.076701.

Erol, A.O., 1989. Engineering geological considerations in a salt dome region surrounded by sabkha sediments, Saudi Arabia. Engineering Geology, 26(3), pp.215232.

Irons, J., 2011. Landsat 7 science data user's handbook. NationalAeronautics and Space Administration (NASA).

Latifovic, R., Fytas, K., Chen, J. and Paraszczak, J., 2005. Assessing land cover change resulting from large surface mining development. International Journal of applied earth Observation and Geoinformation, 7(1), pp.29-48. 
Li, X. and Damen, M.C., 2010. Coastline change detection with satellite remote sensing for environmental management of the Pearl River Estuary, China. Journal of Marine systems, 82, pp.S54-S61.

Nicholls, R.J., Wong, P.P., Burkett, V., Codignotto, J., Hay, J., McLean, R., Ragoonaden, S., Woodroffe, C.D., Abuodha, P.A.O., Arblaster, J. and Brown, B., 2007. Coastal systems and low-lying areas.

Petropoulos, G.P., Kalivas, D.P., Griffiths, H.M. and Dimou, P.P., 2015. Remote sensing and GIS analysis for mapping spatio-temporal changes of erosion and deposition of two Mediterranean river deltas: The case of the Axios and Aliakmonas rivers, Greece. International Journal of Applied Earth Observation and Geoinformation, 35, pp.217-228.

Schmidt, H. and Glaesser, C., 1998. Multitemporal analysis of satellite data and their use in the monitoring of the environmental impacts of open cast lignite mining areas in Eastern Germany. International Journal of Remote Sensing, 19(12), pp.2245-2260.

Stats.gov.sa. 2016. General Authority for Statistics. [online] Available at: https://www.stats.gov.sa/en/node.

Thampanya, U., Vermaat, J.E., Sinsakul, S. and Panapitukkul, N., 2006. Coastal erosion and mangrove progradation of Southern Thailand. Estuarine, coastal and shelf science, 68(1-2), pp.7585.

Youssef, A.M., Pradhan, B., Sabtan, A.A. and El-Harbi, H.M., 2012. Coupling of remote sensing data aided with field investigations for geological hazards assessment in Jazan area, Kingdom of Saudi Arabia. Environmental Earth Sciences, 65(1), pp.119-130. 